
J. Egypt. Soc. Parasitol. (JESP), 51(2), 2021: 297 - 304

(Online: 2090-2549)

\title{
IMPROVEMENT OF SNAKE ANTISERA PRODUCTION USING NEW INNOVATIVE ADJUVANTS (W/O FORMULATION)
}

\author{
By \\ ABIR A. ELFIKY ${ }^{1 *}$, AYMAN A. DIAB ${ }^{2}$, MONA A. KHAMIS ${ }^{2}$ \\ and AYMAN T. A. MORSY ${ }^{3}$
}

Director, Anti-venom Research, (VACSERA), Dokki ${ }^{*}$, Giza, Faculty of Biotechnology, 6 October University for Modern Sciences and Arts (MSA) and Consultant Tropical Medicine and Fever ${ }^{3}$, Egypt ( ${ }^{*}$ Correspondence: elfikyabir@gmail.com)

\section{Abstract}

Undoubtedly, the snake anti-venom is a medication made up of antibodies used to treat its bites by venomous snakes. Repeated administration of snake venoms from Spitting cobra, in gradual sub-lethal doses into horses has been reported to cause various ill health conditions to recipient animals beside loss in the antibody titer in the plasma harvested from immunized horses. It could accordingly, propose some amendment in the immunization schedule using different adjuvants to choose the best one giving the maximal amount of antibody beside its max safety measures. Montanide ISA is an alternative to CFA for hyper-activation of immune response in rabbits beside it is considered as adjuvant with high safety margin.

Key words: Egypt, Snake, Anti-venom, Innovative adjuvants

\section{Introduction}

The snakebite envenoming is a frequently overlooked cause of mortality and morbidity (Hunter et al, 2019). Snakebite envenoming is a neglected tropical disease that exerts a high burden of mortality and morbidity, particularly in impoverished rural regions of Africa, Asia, Latin America and parts of Oceania (Chippaux, 1998). Subgenera Uraeus (F. Elapidae) was a symbol for the goddess widget; she was one of the earliest Egyptian deities and often depicted as a cobra, as she was the serpent goddess (Linnaeus, 1758). The repeated administration of snake venoms from Spitting cobra in gradual sublethal doses into horses caused various health problems and may even death to recipient animals beside the low titer of the antibody produced (Elfiky et al, 2002). A spitting cobra is any of several cobra species that can project venom from their fangs when defending themselves The venom is generally harmless on intact mammalian skin (although contact can result in delayed blistering of the area), but can cause permanent blindness if introduced to eye; if left untreated may cause chemosis and corneal swelling (Young et al, 2004). Some amendment in the dose, time of administration of the venoms and the type of adjuvant used (Angulo et al, 1997). Emulsion adjuvants have been used for production of polyclonal antisera in rabbits (Oryctolagus cunniculi) for decades. Complete Freund's adjuvant has a reputation as a very effective immunoenhancer, but adverse physiological effects, including fever, inflammation and sterile abscess formation, have prompted a search for alternatives to complete Freund's (Johnston et al, 1991). Adjuvants are substances injected along with an antigen that is intended to enhance the humoral and/or cell-mediated immune response to the antigen. Adjuvants generally permit the use of a smaller antigen dose and may modulate immune response to the antigen. More than 100 adjuvant preparations were described (Vogel and Powell, 1995), although many of these adjuvants are used only rarely due to complexity of preparation, expense, or toxic effects (StewartTull, 2003). Adjuvants may be divided arbitrarily into those used for prophylactic purposes, primarily to develop therapeutic vaccines protecting from infectious organisms or toxins, and those used for experimental purpose (Allison and Boyars, 1986).

Preparation of snake anti-venom includes administration of the venom to a suitable animal, mostly horses, and after an appropriate period the specific antibodies were collected from the serum of the inoculated animal. During such procedure the recipient animal 
may suffer different types of ill-health signs (Russell, 1983). The severity and duration of the clinical signs depended on the nature, amount and injected site (Rosenberg, 1990). The immunologic adjuvants are agents that nonspecifically increase immune responses to specific antigens that are weakly immunogenic, and the responses induced by Montanide adjuvants were mild and transient compared with those induced by CFA (Bennett et al, 1992). The WHO formulations induced strong and long term immunity that allowed the antigen concentration reduction as cost effective, as well as they could enhance the cellular and humeral immune response (Bahnemann and Mesquita, 1987).

The present work was designed to study the effect of giving sub-lethal doses of snake venom (Spitting cobra) accompanied with $\mathrm{W} / \mathrm{O}$ adjuvant in the framework of preparation of their antivenin represented by determination of safety and efficacy of this new adjuvant compared with the traditional one [Complete Freund's Adjuvants (CFA)].

\section{Materials and Methods}

The animals were used 1- Mice: Twenty five mice wt. 18-20gm were used to determine serum antibody potency in the immunized animals. 2- Newzeland Rabbits: 18 were divided into 3 groups each of 6 rabbits wt. $3.0-3.5 \mathrm{Kgm}$ were used to evaluate the safety and effecasy of Montanide adjuvants (Monanide ISA 50, \& Montanide ISA 70) in compared with the tradi-tional adjuvant (CFA). During the vaccination period, which lasted for months, the animals were keenly and regularly observed for any ill-health condition, abnormal signs, or ailment were reported and clinically interpreted.

Serum samples: About $5 \mathrm{ml}$ whole blood from each rabbit were taken simultaneously in vacutainers but without addition of any anticoagulant. The obtained serums were used for determination of antibody titre against spitting cobra venom.

Venom: Spitting cobra venom were obtained from VACSERA venom stored in dry form. Just prior to inoculation into the recipient animal, the venom was dissolved in 0.5 $\mathrm{ml}$ sterile saline/dose of the venom. Adjuvants were oily adjuvants ready to use formulations of pharmaceutical oils and highly purified surfactants to produce antibodies.

Complete freund's adjuvant (CFA), Sigma, USA): CFA is a water-in-oil emulsion of mineral oil, mannide monooleate (a surfactant), and heat-killed Mycobacterium tuberculosis, Mycobacterium butyricum, or organism components (Freund, 1951), which was considerd as the most inflammatory component of CFA, commonly used for the immunizations in initial injection

Montanide 70VG (Seppic, France) was used at an adjuvant mixtured with antigen at ratio of 30/70 (v/v) according to manufacturer's instructions. Montanide (Incomplete Seppic adjuvants), is an oil adjuvant composed of a natural metabolizable oil and a highly refined emulsifier from the manide monooleate family (Aucouturier et al, 2002).

Table 1: Different adjuvants used

\begin{tabular}{|c|c|c|c|}
\hline Type of adjuvants & Montanide ISA 50 & Montanide ISA 70 & Complete freund's djuvants ( CFA) \\
\hline Ratio Ag/oil & $50 / 50$ & $70 / 30$ & $50 / 50$ \\
\hline Viscosity & $200 \mathrm{cps}$ & $500 \mathrm{cps}$ & ------cps \\
\hline Syringability $\left(\right.$ viscosity $\left.^{-1}\right)$ & $0.7-0.9 \mathrm{~Pa}^{-1} \cdot \mathrm{S}^{-1}$ & $1.7-1.9 \mathrm{~Pa}^{-1} \cdot \mathrm{S}^{-1}$ & $1.7-1.9 \mathrm{~Pa}^{-1} \cdot \mathrm{S}^{-1}$ \\
\hline
\end{tabular}

Emulsion and formulation: Venom and adjuvants were well mixed to form emulsion befor use, $0.5 \mathrm{ml}(50 / 50)$ of the immunogen formulation (venom emulsion) was given subcutaneously according to immunization schedules. Three groups of adjuvants were assessed in each group (Montanide ISA-50, Montanide ISA-70, \& CFA), sera were taken before each dose to determinate the dose effect on the antibody production.

Preparing CFA antigen-adjuvant emulsion posed additional problems. Current methods for adjuvant-antigen emulsion preparation include commercially available double-hubbed needles and homogenizers. The goal in all cases was to prepare a stable water-in-oil emulsion by maximizing the depot effect of CFA. To test completeness of the emulsific- 
ation, a drop of the antigen-FCA emulsion was put onto the surface of a cold water bath--a properly prepared emulsion would not spread on the surface16. Another characteristic of a properly prepared emulsion was high viscosity, necessitating the use of luerlock syringes (preferably glass, since the oil reacts with the rubber plunger on disposable plastic syringes) and 23 gauge or larger needles for injection. Unless one used 20 gauge or larger needles injecting the emulsion must require substantial force It was indicated to use Freund's larger needles, injecting the emulsion should require substantial force. It was a must for the involved members to avoid the risky accidental inoculation.

Preparation of rabbits' antisera: Immunization with spitting cobra venom was done in 18-male rabbits. Each dose group consisted of six rabbits; G1: rabbit received the venom mixed with CFA subcutaneously (S.C.), G2: mixed with the new adjuvant Montanide ISA 50, \& G3: mixed with new adjuvant Montanide ISA 70. Venom was injected as emulsified with adjuvant until $3^{\text {th }}$ immunization, and then plain solution was used. By stepwise increments of the immunizing dose lasted for 35 days. Rabbits were sacrificed a week after the last immunization. Anti-lethal activity of the immunized antiserum was determined to evaluate antibody potency.

Preparation of venom: Stable preparations were done by mixing the aqueous medium containing venom into Montanide ISA, or CFA with vigorous stirring to produce stable emulsion for immediate injection. Table 2: Immunization schedules (Helwan schedule, VACSERA)

\begin{tabular}{|l|c|c|}
\hline Day & sampling & Rabbit dose \\
\hline 0 & & $50 \mu \mathrm{g}+$ Adj \\
\hline 7 & Serum Sample & $70 \mu \mathrm{g}+$ Adj. \\
\hline 14 & Serum Sample & $100 \mu \mathrm{g}+$ Adj. \\
\hline 21 & Serum Sample & $100 \mu \mathrm{g}+$ saline \\
\hline 28 & Serum Sample & $150 \mu \mathrm{g}+$ saline \\
\hline 35 & Serum Sample & $200 \mu \mathrm{g}+$ saline \\
\hline 42 & Serum Sample & ------ \\
\hline
\end{tabular}

Safety checked by assessed local reactions due to signs of local reaction at schedule at injection site. Its intensity was defined time in each group as following schedule: Table 3: Grades of signs

\begin{tabular}{|l|l|}
\hline Grade & Signs \\
\hline 0 & no local reaction \\
\hline 1 & small local reaction $<1 \mathrm{~mm}$ \\
\hline 2 & small local reaction $<5 \mathrm{~mm}$ \\
\hline 3 & local reaction $<1 \mathrm{~cm}$ \\
\hline 4 & local reaction $>1 \mathrm{~cm}$ \\
\hline
\end{tabular}

The montanide adjuvants were considered safe by the Committee for Veterinary Medical Pro-ducts (CVMP) for use in immunological products and included in annex II of the European Council Regulation 2377/90/ EC; needing no further MRL studies nor included in registered veterinary commercial products (Marrack et al, 2009).

The spitting cobra potency evaluation $\left(\mathrm{LD}_{50}\right)$ in mice (Abdou et al, 2017): Prepare graded dilutions of the reconstituted venom in a $9 \mathrm{~g} / \mathrm{l}$ solution of sodium chloride $\mathrm{R}$ or other isotonic diluent in such a manner that middle dilution contained $0.25 \mathrm{ml}$ the dose to be $\mathrm{LD}_{50}$.
Dilute with an equal volume of same diluent. Using 4 mice, each weighed $18-20 \mathrm{~g}$, for each dilution, inject $0.5 \mathrm{ml} \mathrm{I.V.,} \mathrm{and} \mathrm{followed}$ up for $48 \mathrm{~h}$ to record deaths. Calculate the $\mathrm{LD}_{50}$ using the usual statistical methods. Allow the mixtures to stand in a water-bath at $37^{\circ} \mathrm{C}$ for $30 \mathrm{~min}$. Using not less than 6 mice, each weighing $18-20 \mathrm{~g}$, for each mixture, inject $0.5 \mathrm{ml}$ intravenously into each mouse, observed for $48 \mathrm{~h}$ and record deaths number. Calculate the $\mathrm{PD}_{50}$, and at the same time verify the number of $\mathrm{LD}_{50}$ in venom dolse. Calculate antiserum potency from expression:

$\underline{\mathrm{TV}-1}$, as TV $=\mathrm{LD}_{50}$ No. in venom dose. 
In each mouse dose of venom-antiserum mixture at the end point was one $\mathrm{LD}_{50}$ of venom remaining un-neutralized by the antiserum and it is this neutralized venom that is responsible for the deaths of $50 \%$ of mice inoculated with the mixture. Venom neutralized amount by antiserum was thus $\mathrm{LD}_{50}$ less than total amount contained in each mouse dose. Potency of antiserum in terms was $\mathrm{LD}_{50}$ number of venom that was neutralized rather than $\mathrm{LD}_{50}$ number in each mouse dose. Expression required in the calculation of potency was TV-1 rather than TV.
Alternatively, the quantity of test venom in milligrams that is neutralized by $1 \mathrm{ml}$ or some other defined volume of the antiserum to be examined may be calculated.

Statistical analysis: Data were tabulated and analyzed. Comparison among groups for significance was done by t-test represented by mean \pm SD (Kirkwood and Sterne, 2003)

\section{Results}

The $\mathrm{LD}_{50}$ of spitting venom were determined and calculated for tested venom before its use in immunization of rabbits to produce spitting cobra anti-venom (Tab. 3).

Table 3: LD50 of spitting cobra venom

\begin{tabular}{|c|c|c|c|c|c|}
\hline Dose & \multicolumn{2}{|c|}{ Directly observed } & \multicolumn{2}{c|}{ Corrected } & Death\% \\
\hline$\mu \mathrm{g} /$ mouse & Death & Survival & Death & Survival & \\
\hline 7 & 1 & 4 & 1 & 10 & 09.0 \\
8.4 & 2 & 3 & 3 & 6 & 33.3 \\
10.8 & 3 & 2 & 6 & 3 & 66.6 \\
12 & 4 & 1 & 10 & 1 & 90.9 \\
\hline
\end{tabular}

Serum potency detected antibodies produced against spitting cobra venom $t$ neutralized $1 \mathrm{ml}$ of immunized serum. $\mathrm{ED}_{50}$ was not significant increase in all rabbits groups injected with spitting cobra after $1^{\text {st }} \& 2^{\text {nd }}$ doses of venom during immunization period whatever was the type of adjuvant used. After third injection dose, there was significant

increase $(\mathrm{P} \leq 0.05)$ in antibody titers in $\mathrm{G} 1 \&$ G2 than in G3. After fourth dose of injection, there was significant increase $(\mathrm{P} \leq 0.01)$ in $\mathrm{G} 2 \& \mathrm{G} 3$ than in G1. Aft-er $5^{\text {th }} \& 6^{\text {th }}$ venom doses, there was increase in antibody titer than the previous third and fourth doses but without significance differences between these groups (Tab. 4).

Table 4: Antibody potency under different adjuvants during immunization schedules to produce spitting venom antisera

\begin{tabular}{|c|c|c|c|c|c|c|}
\hline Dose & day & $*$ sampling & Rabbit dose & G1 $(/ \mathrm{ml})$ & G2 $(/ \mathrm{ml})$ & $\mathrm{G} 3(/ \mathrm{ml})$ \\
\hline 0 & 0 day & Serum Sample & $50 \mu \mathrm{g}+$ Adjuvant & 0 & 0 & 0 \\
\hline 1 & After 1 week & Serum Sample -1 & $70 \mu \mathrm{g}+$ Adjuvant & $3.9 \pm 1.19 \mathrm{IU}$ & $3.5 \pm 1.04 \mathrm{IU}$ & $3.0 \pm 0.89 \mathrm{IU}$ \\
\hline 2 & After 2 week & Serum Sample-2 & $100 \mu \mathrm{g}+$ Adjuvant & $5.3 \pm 0.51 \mathrm{IU}$ & $5.3 \pm 0.54 \mathrm{IU}$ & $5.3 \pm 0.51 \mathrm{IU}$ \\
\hline 3 & After 3 week & Serum Sample -3 & $100 \mu \mathrm{g}+$ saline & $10^{*} \pm 1.12 \mathrm{IU}$ & $10^{*} \pm 1.12 \mathrm{IU}$ & $8 \pm 1.41 \mathrm{IU} / \mathrm{ml}$ \\
\hline 4 & After 4 week & Serum Sample-4 & $150 \mu \mathrm{g}+$ saline & $12.7 * \pm 0.649 \mathrm{IU}$ & $14.5 \pm 1.643 \mathrm{IU}$ & $15.25 \pm 0.758 \mathrm{IU}$ \\
\hline 5 & After 5 week & Serum Sample-5 & $200 \mu \mathrm{g}+$ saline & $20 \pm 1.02 \mathrm{IU}$ & $20 \pm 1.02 \mathrm{IU}$ & $20 \pm 1.20 \mathrm{IU}$ \\
\hline 6 & After 6 week & Serum Sample-6 & ----------- & $26 \pm 1.41 \mathrm{IU}$ & $25 \pm 1.41 \mathrm{IU}$ & $25 \pm 1.54 \mathrm{IU}$ \\
\hline
\end{tabular}

Blood sample before injection of recommended venom dose, Result $=\mathrm{M} \pm \mathrm{SD},{ }^{*} \mathrm{P} \leq 0.05,{ }^{* * \mathrm{P}} \leq 0.01,{ }^{* * * \mathrm{P} \leq 0.005}$

Close daily observation of the rabbits given sub-lethal doses of snake venoms (Spitting cobra) showed irritation and swelling as a concomitant sign at injection site. Intensity differed between injected groups (Tab. 5), but, from case to case, increased generally during the $1^{\text {st }}$ immunization mainly at G3, with complete Freund's adjuvant (CFA).

Table 5: Evaluation of local reaction in immunized rabbits

\begin{tabular}{|l|c|l|l|c|}
\hline \multicolumn{1}{|c|}{ Injection time } & dose & G1 (Montanide ISA 50) & G2 (Montanide ISA 70) & G3 (CFA) \\
\hline 0 day & $50 \mu \mathrm{g}+$ Adj & Grade 1 & Grade 1 & Grade 3 \\
\hline After 1 week & $70 \mu \mathrm{g}+$ Adj. & Grade 1 & Grade 1 & Grade 2 \\
\hline After 2 week & $100 \mu \mathrm{g}+$ Adj. & Grade 1 & Grade 1 & Grade 2 \\
\hline After 3 week & $100 \mu \mathrm{g}+$ saline & Grade 1 1 \\
\hline After 4 week & $150 \mu \mathrm{g}+$ saline & Grade 1 & Grade 1 & Grade 1 \\
\hline After 5 week & $200 \mu \mathrm{g}+$ saline & Grade 1 & Grade 1 & Grade 1 \\
\hline After 6 week & ---- & Grade 1 & No local reaction \\
\hline
\end{tabular}


Safety of liver and kidney profiles was measured for both the Montanide' adjuvants groups and complete Freud's Adjuvant ones compared to control. Enzymes showed nonTable 6: Effect of $N$. nigricollis immunization on significant changes in G1 \& G2 compared G3 showed mild significant increase in ALT, urea, and creatinine levels but without marked change in ALT enzyme (Tab. 6).

Table 6: Effect of N. nigricollis immunization on liver and kidney functions in serum of three groups
\begin{tabular}{|l|c|c|c|c|}
\hline Parameter & Control & G1 (Montanide ISA 50) & G2 (Montanide ISA 70) & G3 (CFA) \\
\hline ALT (U/L) & $9.24 \pm 0.11$ & $7.06 \pm 0.521$ & $8.09 \pm 0.21$ & $9.06 \pm 0.82$ \\
\hline AST (U/L) & $4.63 \pm 0.10$ & $8.25 \pm 0.02$ & $10.25 \pm 0.27$ & $18.25 \pm 0.29^{*}$ \\
\hline Urea (mg/dl) & $46.86 \pm 1.8$ & $46.2 \pm 0.5$ & $42.3 \pm 0.41$ & $52.13 \pm 0.581^{*}$ \\
\hline Creatinine (mg/\%) & $0.23 \pm 0.01$ & $0.21 \pm 0.02$ & $0.22 \pm 0.01$ & $0.31 \pm 0.019^{*}$ \\
\hline
\end{tabular}

\section{Discussion}

The history of anti-venom began with the work of the French physician Albert Calmette in the late Nineteenth century, who was given the opportunity to direct a new Pasteur Institute in Saigon, French Indochina (now Ho Chi Minh City, Vietnam), where he started his research on vaccination against rabies and smallpox in 1891 (Hawgood, 1999). A patient managed with snake bite was influenced by the nature of offending snake, its diagnosis based on patient's history and physical signs was often unreliable and possibility of making a species diagnosis by immunological means was investigated (Greenwood et al, 1974). Diphtheria played a key role in establishing bacteriological model for explaining infectious disease, its most effective treatment is swift administration of diphtheria antitoxin (DAT) with conjunct antibiotic therapy. DAT is an equine immunoglobulin preparation and listed among WHO Essential Medicines (Both et al, 2014). Yellow fever virus (YFV), a member of the Flaviviridae family, is Aedes aegypti borne virus that causes viral hemorrhagic fever (El-Bahnasawy et al, 2015). Al-Agroudi et al. (2018) reported malaria in an Egyptian Fever Hospital, and added that infection began when Plasmodium-infected Anopheles vector feed on malaria infected patient. During this probing process, mosquitoes inject saliva with sporozoites into the host skin, and components of Anopheles saliva have a potential to influence sporozoite functionality. Chuang et al. (2020) found that sporozoite-associated the saliva protein 1 (SAMSP1, AGAP013726) was among several proteins identified when sporozoites were isolated from saliva, sug- gesting it to have an effect on Plasmodium. They added that the active or passive immunization of mice with SAMSP1 and/or SAMSP1 antisera diminished the initial parasite burden following infection. Passive immunization of mice with SAMSP1 antisera also added to the protective effect of a cir-cumsporozoite protein monoclonal antibody (Schleicher et al, 2018). Thus, the Anopheles saliva protein influenced sporozoite infectivity in the human host. Ivanov et al. (2020) reported that the only currently available live vaccine against yellow fever (YF) based on the chicken embryos infected with an attenuated 17D strain of the YF virus was one of the most effective vaccine preparations. They added that laboratory version of cultural inactivated vaccine against YF, which is not inferior in immunogenicity (in animal model) to commercial live vaccine. AbdelAziz et al. (2019) gave an up-to-date survey on pharmacology of snake-venom bioactive components and evaluated their therapeutic perspectives against a wide range of pathophysiological conditions. Snake venoms are complex mixtures; mainly proteins, which have enzymatic activities, as protein and peptides made $90-95 \%$ of the venom dry, and weight (Freund et al, 1942). The snake venoms contain inorganic cations such as sodium, calcium, potassium, magnesium and little amounts of zinc, nickel, cobalt, iron, and manganese. Also, some snake venoms contained carbohydrate, lipid, biogenic amines and free amino acids (Sanz et al, 2008). Other snake venoms contain at least 25 enz-ymes, which are protein in nature, but few depend on the certain non-protein prosthetic groups or cofactors. Sublethal doses of Naja 
haje venom caused marked clinical and pathological changes in heart, liver, kidney, and brain of rats (El-Fiky, 1999). Enzymes sublethal injected rats with $N$. nigricollis venom caused severe irritation and swelling (Qteishat et al, 1985). Complete Freund's adjuvant was the widely used to produce immune sera in laboratory animals that caused pain, distress, and pathologic lesions. Institutional of the Animal Care and Use Committees' (IACUC) reported about experimental protocols that involve CFA often have little or no scientific data as a basis (Freund, 1956). The WT1 peptide vaccine with Montanide as an adjuvant induces detectable WT1specific $\mathrm{CD}^{+} \mathrm{T}$ cell responses with clonal TCR enrichment that control leukemia recurrence in setting of minimal residual disease (Liu et al, 2018). It was difficult to assess the presence of pain or distress associated with adjuvant injections. Injection sites that develop an acute inflammatory cell response appear painful from the clinical point of view. Scratching, chewing, and selfmutilation of the site are all signs of pain and/or irritation (Morsy et al, 1994). There was a significant correlation between the ability of anti-ven-om to neutralize the proteolytic and hemorrhagic effects. In spite of the ability of anti-venom to neutralize hemorrhage when incubated with venom prior to injection, hemorrhage was partially neutralized with anti-venom given I.V. at different time periods after envenomation (Gutierrez et al, 2017). In the present study (G1 \& G2) lesions were relatively neither painful nor pruritic compared to G3.

Safety study represented at first by pain and inflammatory response to adjuvants in primary immunization showed that Montanide adjuvants were safer than the complete Fruend's adjuvant (CFA) that causing mini local reaction $<1 \mathrm{~mm}$ at the immunization time along the study period, but CFA caused small local reaction $<5 \mathrm{~mm}$ at first immunization dose, and local reaction $<1 \mathrm{~cm}$ at $\mathrm{sec}$ ond and third immunization doses. The CFA reaction showed that it might cause inflam- mation, induration, or necrosis in experimental animals. Montanide adjuvants caused normal liver and kidney enzyme changes compared with controls but Freund's adjuvant showed slight release in these enzymes.

AST \& ALT enzymes assessed and monitored liver inflammation and necrosis resulting in the enzymes release of in circulation due to increased permeability of cell membrane or cells breakdown (Al-Sadoon et al, 2013). Cobra venom in animals increased AST \& ALT levels. This agreed with Alam (2014) for $N$. nigricollis in rats.

In the present study, montanide adjuvants caused significant increase in antibody titer after $3 \& 4$ weeks of $1^{\text {st }}$ immunization compared with CFA group, but $2^{\text {nd }}$ one gave the same antibody titer in all groups with similar adjuvant effect on immune system (Bergmann and Leitner, 2014). Several biochemical and hematological changes occurred during production of snake anti-venom, although conventional adjuvants like Fr-eund's (complete \& incomplete) were good immuno-potentiates, they produced local reactions in animal, but montanide adjuvants was a safe alternative for the primary phase of immunization in antivenom production (Waghmare et al, 2014).

\section{Conclusion}

Discovery of serum therapy paved the way for human therapies, including envenoming therapy. Freund's complete adjuvant gave exceptional immune response with a severe tissue damage, discomfort, and distress.

The Montanide adjuvant proved to be a good alternative for the hyper-activation of immune response in rabbits with high safety margin.

\section{References}

Abdel-Aziz, T, Soares, A, Stockand, J, 2019: Snake venoms in drug discovery: valuable therapeutic tools for life saving. Toxins (Basel); 2019 Oct; 11(10):564. Published online 2019 Sep

Abdou, F, Denshary, EE, Shaaban, E, Mohamed, M, 2017: Assessment of the neutralizing potency of antisera raised against native $\& \gamma$-irradiated Naja nigricollis (black necked spitting Cobra) venom in rabbits, concerning its cardiot- 
oxic effect. Hum. Exp. Toxicol. 36, 12:1335-44. Al-Agroudi, MA, Ahmad, GMS, Kondo, MK, Morsy, TA, 2018: Malaria situation in Egypt the last three years: Retrospective study in an Egyptian Fever Hospital. J. Egypt. Soc. Parasitol 48, 3:635-44.

Alam, MI, 2014: Inhibition of toxic effects of viper and cobra venom by Indian Medicinal Plants. Pharmacol. Pharmac. 5:828-37.

Allison, AC, Boyars, NE, 1986: The adjuvant formulation that selectively elicits the formation of anti-bodies of protective isotypes and cell-mediated immunity. J. Immunol. Meth. 95:157-68. Al-Sadoon, MK, Abdel Moneim, AE, Bauomy, AA, Diab MSM, 2013: Hepatic and renal tissue damages induced by Cerastes cerastes gasperetti crude venom. Life Sci. J. 10, 4:191-7.

Angulo, Y, Estrada, R, Gutierrez, JM, 1997: Clinical and laboratory investigation in horses during immunization with snake venom for the production of polyvalent Crotalinae anti-venom. Toxicon 35, 1:81-90.

Anthony, TT, 1977: Venom Chemistry, and Molecular Biology. John Willy \& Sons, Inc., New York, London, Sydney, Toronto.

Aucouturier, J, Dupuis, L, Deville, S, Acarateil, S, Ganne, V, 2002: Montanide ISA 720 and 51: A new generation of water in oil emulsions as adjuvants for human vaccines. Expert. Rev. Vaccines 1:111-8.

Bahnemann, H, Mesquita, JA, 1987: Oil adjuvant vaccine against foot and mouth disease. Bol. Centr. Panam. Fiebre Aftosa 53:25-30. Bennett, B, Check, IJ, Olsen, MR, Hunter, R L, 1992: Acomparison of commercially available adjuvants for use in research. J. Immunol. Meth. $153,1 / 2: 31-40$

Bergmann, SE, Leitner, WW, 2014: Adjuvants in the driver's seat: How magnitude, type, fine specificity and longevity of immune responses are driven by distinct classes of immune potentiates. Vaccines (Basel) 2, 2:252-96

Both, L, White, J, Mandal, S, Efstratiou, A, 2014: Access to diphtheria antitoxin for therapy and diagnostics. Euro Surveill. 19, 24:20830. doi: 10.2807/1560-7917

Chuang, YM, Agunbiade, TA, Tang, XD, Freudzon, M, Almeras, L, et al, 2020: A mosquito salivary protein facilitates sporozoite traversal of host cells. J. Infect. Dis. 2020 Dec 11:jiaa759. doi: 10.1093 .

Longbottom, J, Shearer, FM, Devine, M, Alcoba, G, Chappuis, F, et al, 2018: Vulnerabili- ty to snakebite envenoming: A global mapping of hotspots. Lancet 392, 10148:673-84.

El-Bahnasawy, MM, Megahed, LA, Saleh, H AA, Morsy, TA, 2015: Training program for the nursing staff regarding the viral hemorrhagic fevers (VHFs) in a fever hospital. J. Egypt. Soc. Parasitol. 45, 2:249-72

El-Fiky, AM, 1999: Hyperglycemic effect of a neurotoxic fraction (F3) from Naja naja venom: Role of hypothalmopituitary adrenal axis (HPA). J. Nat. Toxins 8, 2:203-12.

El-Fiky, AA, Elsaify AA, Abdou, OA, 2002: Effect of snake venom administration on health status of horses (MVSC): Presented to Semin. Fac. Vet. Med. Cairo University, Giza

Freund, J, 1951: Effect of paraffin oil and mycobacteria on antibody formation and sensitization: A review. Am. J. Clin. Pathol. 21:645-56. Freund, J, 1956: The mode of action of immunologic adjuvants. Adv. Tuberc. Res. 7:130-48.

Freund, J, McDermott, K, 1942: Sensitization to horse serum by means of adjuvants. Proc. Soc. Exp. Biol. Med. 49:548-53.

Greenwood, BM, Warrell, DA, Davidson, N M, Ormerod, LD, Reid, HA, 1974: Immunodiagnosis of snake bite. Br. Med. J. 4, 5947:743-5.

Gutierrez, JM, Solano, G, Pla, D, Herrera, M, Segura, A, et al, 2017: Preclinical evaluation of the efficacy of anti-venoms for snakebite envenoming: State-of-the-art and challenges ahead. Toxins (Basel) 9, 5:163-74.

Hawgood, BJ, 1999: Doctor Albert Calmette 1863-1933: founder of antivenomous serotherapy and of anti-tuberculous BCG vaccination. Toxicon. 37, 9:1241-58.

Hunter, CJ, Piechazek, KH, Nyarang'o, PM, Rennie, T, 2019: Snakebite envenoming. Lancet 393, 10167:129-31.

Ivanov, AP, Klebleeva, TD, Rogova, YV, Ivanova, OE, 2020: Development of inactivated cultural yellow fever vaccine. Vopr. Virusol. 65, 4:212-7

Johnston, BA, Eisen, H, Fry, D, 1991: An evaluation of several adjuvant emulsion regimens for the production of polyclonal antisera in rabbits. Lab. Anim. Sci. 41, 1:15-21.

Kirkwood, BR, Sterne, J, 2003: Essential Medical Statistics. $2^{\text {nd }}$ ed. Oxford: Blackwell Science. Linnaeus, C, 1758: Systema naturæ per regnatria naturæ, secundum classes, ordines, genera, species, cum characteribus, diferentiis, synonymis, locis. Tomus I. Editio Decima, Reformata. Stockholm: L. Salvius, 824pp. (Coluber haje new 
species, 225pp. (in Latin).

Liu, H, Zha, Y, Choudhury, N, Malnassy, G, Fulton, N, et al, 2018: WT1 peptide vaccine in Montanide in contrast to poly ICLC is able to induce WT1-specific immune response with TCR clonal enrichment in myeloid leukemia. Exp. Hematol. Oncol. Jan 11;7:1. doi: 10.1186/s401

Marrack, P, McKee, AS, Munks, MW, 2009: Towards an understanding of the adjuvant action of 312 aluminium. Nat. Rev. Immunol. 9:287-93

Morsy, TA, Zohdi, HW, Abdalla, KF, el Fakahani, AF, Ibrahim, AA, et al, 1994: Isolation of three species of mites from house dust of atopic dermatitis patients in Qualyobia Governorate, Egypt. J. Egypt. Soc. Parasitol. 24, 2:323-31. Qteishat, WA, Whitehouse, GH, Hawass, NE, 1985: Acro-osteolysis followed snake and scorpion envenomation. Br. J. Radiol. 58, 695:1035-9. Rosenberg, P, 1990: Phospholipases. In: Handbook of Toxicology; Shier, WT, Mobs, D, (eds.) Marcel Dekker, New York.

Russell, FE, 1983: Snake Venom Poisoning. Philadelphia, Lippincott: Great Neck. NY: Scholium International Publications.

Sanz, L, Ayvazyan, N, Calvete, J, 2008: Snake venomous of the Armenian Mountain Vipers macrovipera lebetina obtusa and Vipera raddei. J. Proteomics 71:198-209.

Schleicher, T, Yang, J, Freudzon, M, Rembisz, A, Craft, S, et al, 2018: A mosquito salivary gland protein partially inhibits Plasmodium sporozoite cell traversal \& transmission. Nat. Commun. 91:2908.doi:10.1038/s41467-018-05374-3.

Vogel, FR, Powell, MF, 1995: A compendium of vaccine adjuvants and excipients. In: Vaccine Design: The Subunit \& Adjuvant Approach. Powell, MF, Newman, MJ (Eds.). New York, Plenum Press

Young, BA, Dunlap, K, Koenig, K, Singer, M, 2004: The buccal buckle: The functional morphology of venom spitting in cobras. J. Exp. Biol. 207, 20:3483-94.

Waghmare, AB, Salvi, NC, Deopurkar, RL, Shenoy, PA, Sonpetkar, JM, 2014: Evaluation of health status of horses immunized with snake venom and montanide adjuvants, IMS 3012 (nanoparticle), ISA 206 and ISA 35 (emulsion based) during polyvalent snake antivenom production: hematological and biochemical assessment. Toxicon 82:83-92.

Fig. 1: Antibody potency affected by different adjuvants during immunization schedules for spitting Cobra anti-venom production. Fig. 2: Adjuvants safety in immunized rabbits

Fig. 3: Effect of Naja nigricollis (spitting cobra) immunization on liver and kidney functions in sera of three groups.

Fig. 4: Green glazed cobra amulet of genus Uraeus
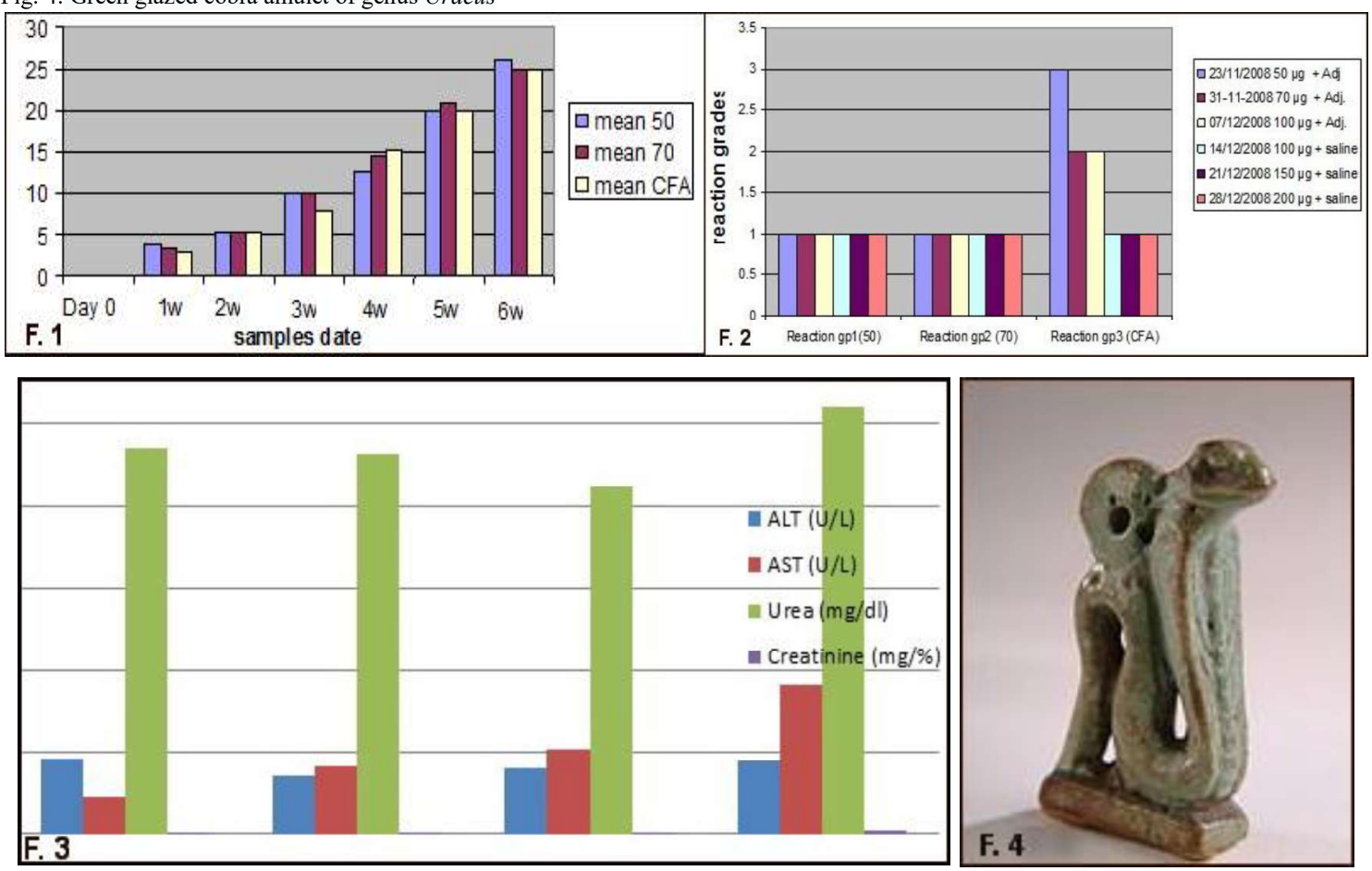